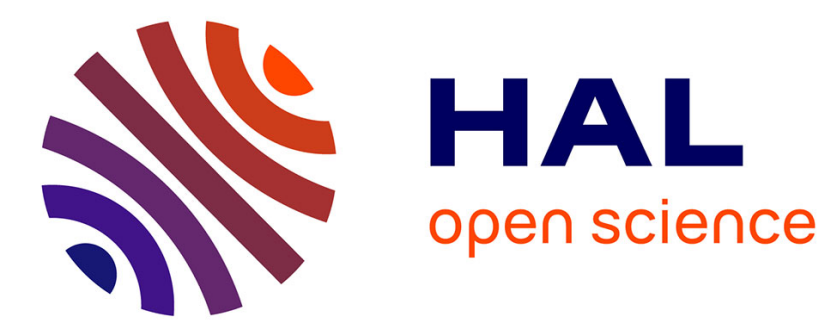

\title{
Characterization of a medical interface
}

\author{
A. Janot, C. Bidard, M. Gautier, F. Gosselin, D. Keller, Y. Perrot
}

\section{To cite this version:}

A. Janot, C. Bidard, M. Gautier, F. Gosselin, D. Keller, et al.. Characterization of a medical interface. 2007 IEEE International Symposium on Industrial Electronics, Jun 2007, Vigo, Spain. pp.2071-2076, 10.1109/ISIE.2007.4374927 . cea-03254586

\section{HAL Id: cea-03254586 https://hal-cea.archives-ouvertes.fr/cea-03254586}

Submitted on 8 Jun 2021

HAL is a multi-disciplinary open access archive for the deposit and dissemination of scientific research documents, whether they are published or not. The documents may come from teaching and research institutions in France or abroad, or from public or private research centers.
L'archive ouverte pluridisciplinaire HAL, est destinée au dépôt et à la diffusion de documents scientifiques de niveau recherche, publiés ou non, émanant des établissements d'enseignement et de recherche français ou étrangers, des laboratoires publics ou privés. 


\section{Characterization of a medical interface}

\author{
A. JANOT ${ }^{(1,2)}$, C. BIDARD ${ }^{(1)}$, M. GAUTIER ${ }^{(2)}$ \\ ${ }^{(1)}$ CEA/LIST Interactive Robotic Unit \\ 18 route du Panorama, BP 6, 92265 Fontenay aux Roses \\ Cedex, France \\ alexandre.janot@cea.fr, catherine.bidard@cea.fr
}

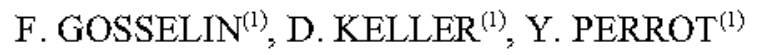 \\ ${ }^{(2)}$ IRCCyN, Robotic team \\ 1, rue de la Noë - BP 92101 - 44321 Nantes Cedex 03, France \\ maxime.gautier@irccyn.ec-nantes.fi, florian.gosselin@cea.fr
}

\begin{abstract}
The medical interface studied in this paper is an haptic interface. These interfaces are robotic devices intended to enhance the user's immersion in virtual environments through the stimulation of the haptic sense. Usually, they consist of an articulated mechanical structure which introduces distortion between the operator and the explored world. In order to assess the quality of the devices, it must be identified. This paper deals with this issue and introduces the characterization of the medical interface. Each 3 degrees of freedom (DOFs) branch uses a parallelogram and double parallelogram loop. The characterization is based on the inverse model and least squares method.
\end{abstract}

\section{INTRODUCTION}

Haptic interfaces aim at the matching between the force and displacements given by the user and those applied to the virtual world Such systems are in growing demands for applications such as force feedback remote-control systems for extreme environment, man-machine interaction and training in professional operating procedures [1].

Usually, haptic interfaces consist of a mechanical actuated structure, such as robots, whose distal link is equipped with a handle. When manipulating this handle to interact with the explored world the user feels a distortion introduced by the dynamic model of the interfaces. This distortion must be identified in order to enhance the design of the device and/or to develop appropriate control laws.

To do so, the system is often modeled as a second order, sometimes with Coulomb friction, as in [2]-[3]. It has also been modeled as a series of second orders [4]. Several techniques of identification have been tested: in [5] the authors identify the device using spectral analysis while pulses are used in [4] to characterize another haptic device and in [6], a parallel interface device is identified by means of relative least squares method and inverse model. In all cases, the distortion is locally identified relying on specific models. In our case, the medical interface exhibits a complex architecture and a strong nonlinear behavior. Thus, these techniques can not be applied as they would not allow characterizing the interface in different positions of the workspace. Therefore, the link parameters must be identified

In [7], a PHANToM ${ }^{\mathrm{TM}}$ was identified using inverse model and least squares method. However, the conditioning number of the linear regression is not considered Hence, it is impossible to know if the trajectories are enough exciting.

In [8]-[9], a parametric identification method adapted to multi DOFs systems, based on inverse model and least squares regression has been successfully applied to industrial robots. This method has been extended to a single DOF haptic interface using a cable transmission. The first results were encouraging [10]. Our purpose is to extend this result to 3 DOFs haptic devices. Therefore, we model and identify the 3 DOFs branches of a medical interface which exhibit a complex architecture consisting of a single and a double parallelogram loop.

The paper is organized as follows: the second section presents the medical interface and its modeling while the identification method and the experimental results are presented in the third section; finally, the performances will be discussed in section 4 .

\section{PRESENTATION AND MODELING OF THE MEDICAL INTERFACE}

\section{A. Presentation}

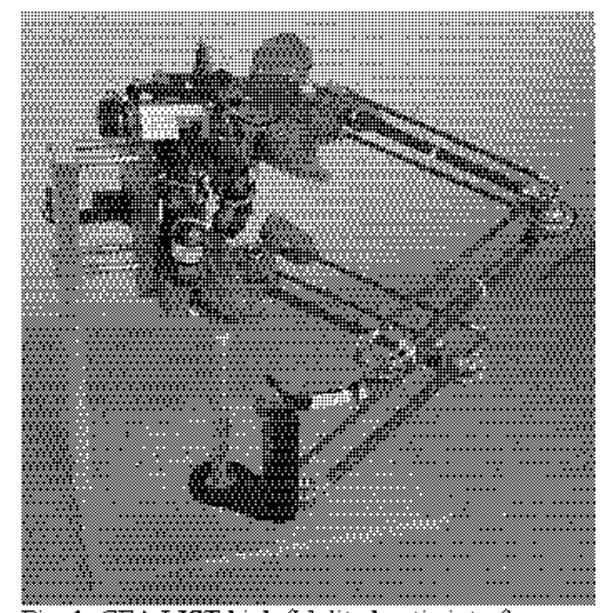

Fig. 1. CEA LIST high fidelity haptic interface

The CEA LIST has recently developed a $6 \mathrm{DOF}$ high fidelity haptic device for telesurgery [12]. As serial robots are quite complex to actuate while fully parallel robots exhibit a limited 
workspace, this device makes use of a redundant hybrid architecture composed of two 3 DOFs branches connected via a platform supporting a motorized handle, having thus a total of 7 motors (Fig. 1).

Each branch is composed of a shoulder, an arm and a forearm lever actuated by a parallelogram loop (Fig. 2). To provide a constant orientation between the support of the handle and the shoulder, a double parallelogram loop is used. Our purpose is to model and identify the serial upper and lower branches of the interface (the handle is disconnected).

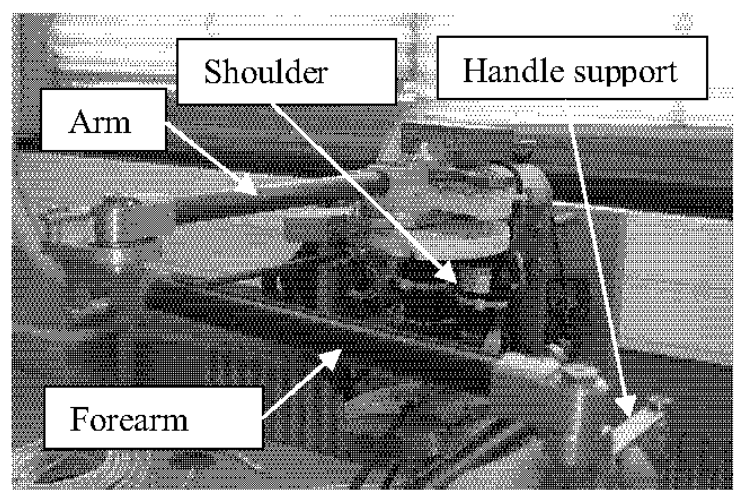

Fig. 2. Upper branch of the medical interface to be identified

\section{B. Modeling}

In this section, the modeling of the upper branch is presented (the modeling of the lower branch being the same). Fig. 3 presents the modified Denavit Hartenberg (DHM) frames of the single parallelogram loop actuating the forearm while Fig. 4 presents the DHM frames of the double parallelogram loop which is modeled as a series of two parallelograms attached to a common mechanical piece. This point of view can be considered as an extension of the reasoning exposed in [11].

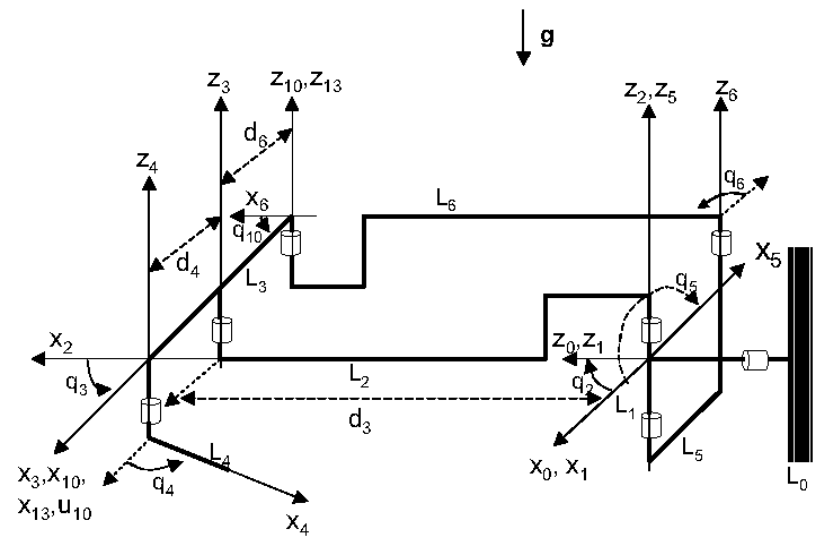

Fig. 3. DHM frames for modeling the single parallelogram loop of the branches of the medical interface

In order to obtain an equivalent tree structure, joints 10,11 and 12 are virtually cut [13]. With respect to the joint numbers defined on Fig. 3 and Fig. 4, we denote for the equivalent tree structure:
- $\mathbf{q}_{\mathrm{a}}=\left[\begin{array}{lll}\mathrm{q}_{1} & \mathrm{q}_{2} & \mathrm{q}_{5}\end{array}\right]^{\mathrm{T}}$ the active joints position vector

- $\mathbf{q}_{\mathbf{p}}=\left[\begin{array}{lllll}\mathrm{q}_{3} & \mathrm{q}_{6} & \mathrm{q}_{4} & \mathrm{q}_{7} & \mathrm{q}_{8} \\ \mathrm{q}_{9}\end{array}\right]^{\mathrm{T}}$ the passive joints position vector

- $\mathbf{q}_{\mathbf{c}}=\left[\begin{array}{lll}\mathrm{q}_{10} & \mathrm{q}_{11} & \mathrm{q}_{12}\end{array}\right]^{\mathrm{T}}$ the cut joints position vector

- $\Gamma_{\mathrm{ar}}=\left[\Gamma_{\mathrm{ar} 1} \Gamma_{\mathrm{ar} 2} \Gamma_{\mathrm{ar} 5} \Gamma_{\mathrm{ar} 3} \Gamma_{\mathrm{ar} 6} \Gamma_{\mathrm{ar} 4} \Gamma_{\mathrm{ar} 7} \Gamma_{\mathrm{ar} 8} \Gamma_{\mathrm{ar} 9}\right]^{\mathrm{T}}$ the joints torque vector of the equivalent tree structure

- $\Gamma_{\mathbf{m}}=\left[\Gamma_{1} \Gamma_{2} \Gamma_{5}\right]^{\mathrm{T}}$ the motorized joints torques

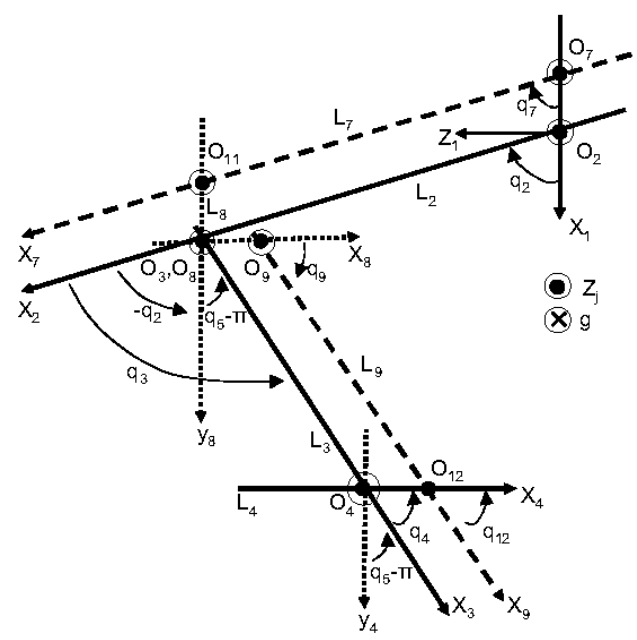

Fig. 4. DHM frames for modeling the double parallelogram loop of the branches of the medical interface

Now, the relations between the variables $\mathbf{q}_{\mathbf{a}}$ and $\mathbf{q}_{\mathbf{p}}$ are calculated. These relations constitute the geometric constraint equations of the closed loops, i.e. $\mathbf{q}_{\mathbf{p}}=\mathbf{f}_{\mathbf{c}}\left(\mathbf{q}_{\mathbf{a}}\right)$ and parallelogram loops give linear constraint equations [11]. Since the links 2, 6 and 7 (resp. 5, 3 and 9) are always parallel, we obtain:

$$
\begin{aligned}
& \mathrm{q}_{3}=\mathrm{q}_{5}-\mathrm{q}_{2}-\pi \\
& \mathrm{q}_{6}=\mathrm{q}_{2}-\mathrm{q}_{5} \\
& \mathrm{q}_{7}=\mathrm{q}_{2} \\
& \mathrm{q}_{9}=\pi / 2+\mathrm{q}_{5}
\end{aligned}
$$

Link 4 and 8 keep a constant orientation with respect to the shoulder. That gives:

$$
\begin{aligned}
& \mathrm{q}_{4}=3 \pi / 2-\mathrm{q}_{5} \\
& \mathrm{q}_{8}=\pi / 2-\mathrm{q}_{2}
\end{aligned}
$$

Finally, the closed loop equations give:

$$
\begin{aligned}
& \mathrm{q}_{10}=\mathrm{q}_{5}-\mathrm{q}_{2}-\pi \\
& \mathrm{q}_{11}=-\mathrm{q}_{2} \\
& \mathrm{q}_{12}=3 \pi / 2-\mathrm{q}_{5}
\end{aligned}
$$

Knowing the constraint equations, the dynamic model of the closed loop chain is given by:

$$
\boldsymbol{\Gamma}_{\mathrm{m}}=\left[\left[\frac{\partial \mathbf{q}_{\mathrm{a}}}{\partial \mathbf{q}_{\mathrm{a}}}\right]^{\mathrm{T}}\left[\frac{\partial \mathbf{q}_{\mathrm{p}}}{\partial \mathbf{q}_{\mathrm{a}}}\right]^{\mathrm{T}}\right] \boldsymbol{\Gamma}_{\mathrm{ar}}=\left[\begin{array}{ll}
\mathbf{I}_{3} & \mathbf{G}^{\mathrm{T}}
\end{array}\right] \boldsymbol{\Gamma}_{\mathrm{ar}}
$$




$$
\boldsymbol{\Gamma}_{\mathrm{m}}=\left[\begin{array}{ccc|cccccc}
1 & 0 & 0 & 0 & 0 & 0 & 0 & 0 & 0 \\
0 & 1 & 0 & -1 & 1 & 0 & 1 & -1 & 0 \\
0 & 0 & 1 & 1 & -1 & -1 & 0 & 0 & 1
\end{array}\right] \boldsymbol{\Gamma}_{\mathrm{ar}}
$$

Thus, (10) describes the couplings in the 3 DOFs branches of the medical interface. Thanks to the constraint equations, the dynamic model can be written as:

$$
\Gamma_{\mathrm{m}}=\mathbf{A}\left(\mathbf{q}_{\mathrm{a}}\right) \ddot{\mathbf{q}}_{\mathrm{a}}+\mathbf{H}\left(\mathbf{q}_{\mathrm{a}}, \dot{\mathbf{q}}_{\mathrm{a}}\right)+\mathbf{F}_{\mathbf{v}} \dot{\mathbf{q}}_{\mathrm{a}}+\mathbf{F}_{\mathrm{c}} \operatorname{sign}\left(\dot{\mathbf{q}}_{\mathrm{a}}\right)+\text { offset }
$$

Where, $\mathbf{q}_{\mathrm{a}}, \quad \dot{\mathbf{q}}_{\mathrm{a}}$ and $\ddot{\mathbf{q}}_{\mathrm{a}}$ are respectively the active joints position, velocity and acceleration vectors, $\mathbf{A}\left(\mathbf{q}_{\mathbf{a}}\right)$ is the inertia matrix, $\mathbf{H}\left(\mathbf{q}_{\mathrm{a}}, \dot{\mathbf{q}}_{\mathrm{a}}\right)$ is the vector regrouping Coriolis, centrifugal and gravity torques, $\mathbf{F}_{v}$ and $\mathbf{F}_{c}$ are respectively the viscous and Coulomb friction matrices and offset is the offset torques vector.

The classical parameters used in (11) are the components $\mathrm{XX}_{\mathrm{j}}, \mathrm{XY}_{\mathrm{j}}, \mathrm{XZ}_{\mathrm{j}}, \mathrm{YY}_{\mathrm{j}}, \mathrm{YZ}_{\mathrm{j}}, \mathrm{ZZ}_{\mathrm{j}}$ of the inertia tensor of link $\mathrm{j}$ denoted ${ }^{j} \mathbf{J}_{j}$, the mass of the link $j$ called $m_{j}$, the first moments vector of link $\mathrm{j}$ around the origin of frame $\mathrm{j}$ denoted ${ }^{\mathrm{j}} \mathbf{M}_{\mathrm{j}}=\left[\mathrm{MX}_{\mathrm{j}}\right.$ $\left.M Y_{j} \quad M_{j}\right]^{T}$, and the friction coefficients $f_{V j}, f_{C j}$. For the motorized joints, we add the actuator inertia called Iaj.

The kinetic and potential energies being linear with respect to the inertial parameters, so is the dynamic model. It can thus be written as:

$$
\Gamma=\mathbf{D}\left(\mathbf{q}_{\mathrm{a}}, \dot{\mathbf{q}}_{\mathrm{a}}, \ddot{\mathbf{q}}_{\mathrm{a}}\right) \boldsymbol{\chi}
$$

Where $\mathbf{D}\left(\mathbf{q}_{\mathrm{a}}, \dot{\mathbf{q}}_{\mathrm{a}}, \ddot{\mathbf{q}}_{\mathrm{a}}\right)$ is a linear regressor and $\boldsymbol{\chi}$ is a vector composed of the inertial parameters. In the following, the subscript "a" is missing because only the active joints are considered.

\section{Base parameters}

The set of base parameters represents the minimum number of parameters from which the dynamic model can be calculated. They can be deduced from the classical parameters by eliminating those which have no effect on the dynamic model and by regrouping some others. In fact, they represent the only identifiable parameters. In [14] a direct and recursive method of calculation of minimum parameters is described. This method is programmed in SYMORO+ and it is efficient for robots having serial or tree structures. For closed loops, the minimum inertial parameters of the equivalent tree structure are a subset of those of the closed loops. Generally, additional relations from the constraint equations occur. These regroupings may be found using the $\mathrm{QR}$ decomposition numerical method [15] or dealing with the analytical equations. Some particular closed loop structures, as parallelogram, enable easier parameter regroupings [11]. In our case, we have calculated the base parameters through the analytical method and compared with those given by the numerical method. There is no difference. Hence, we give the base parameters and the regrouping relations.
The base parameters are:

$Z Z Z_{1 R}, M X_{1 R}, M Y_{1 R}, f_{v 1}, f_{c 1}$, offset $_{1}, X X_{2 R}, X Y_{2 R}, X Z_{2 R}, Y Z_{2 R}$, $\mathrm{ZZ}_{2 \mathrm{R}}, \mathrm{MX}_{2 \mathrm{R}}, \mathrm{MY}_{2}, \mathrm{f}_{\mathrm{v} 2 \mathrm{R}}, \mathrm{f}_{\mathrm{c} 2 \mathrm{R}}$, offset $2, \mathrm{XX}_{3 \mathrm{R}}, \mathrm{XY}_{3 \mathrm{R}}, \mathrm{XZ}_{3 \mathrm{R}}, \mathrm{YZ}_{3 \mathrm{R}}$, $\mathrm{ZZ}_{3 \mathrm{R}}, \mathrm{MX}_{3 \mathrm{R}}, \mathrm{MY}_{3}, \mathrm{f}_{\mathrm{v} 3 \mathrm{R}}, \mathrm{f}_{\mathrm{c} 3 \mathrm{R}}, \mathrm{MY}_{4}, \mathrm{MX}_{5 \mathrm{R}}, \mathrm{MY}_{5}, \mathrm{f}_{\mathrm{v} 5 \mathrm{R}}, \mathrm{f}_{\mathrm{c} 5 \mathrm{R}}$, offset $5, \mathrm{MY}_{6}, \mathrm{MY}_{7}, \mathrm{MY}_{8 \mathrm{R}}$.

The regrouping relations are:

$\mathrm{ZZ}_{1 \mathrm{R}}=\mathrm{ZZ}_{1}+\mathrm{YY}_{2}+\mathrm{YY}_{3}-\mathrm{XX}_{4}+\mathrm{YY}_{5}+\mathrm{YY}_{6}+\mathrm{YY}_{7}-\mathrm{XX}_{8}+\mathrm{YY}_{9}+$ $\ldots \mathrm{m}_{4} \mathrm{~d}_{4}{ }^{2}+\mathrm{m}_{7} \mathrm{~d}_{7}{ }^{2}+\mathrm{m}_{9} \mathrm{~d}_{9}{ }^{2}+\left(\mathrm{m}_{3}+\mathrm{m}_{4}+\mathrm{m}_{8}+\mathrm{m}_{9}\right) \mathrm{d}_{3}{ }^{2}+\mathrm{I}_{\mathrm{a} 1}$

$\mathrm{MX}_{1 \mathrm{R}}=\mathrm{MX}_{1}-\mathrm{m}_{7} \mathrm{~d}_{7}+\left(\mathrm{d}_{7} / \mathrm{d}_{3}\right) \mathrm{MX}_{7}$

$\mathrm{M}_{\mathrm{Y} 1 \mathrm{R}}=\mathrm{M}_{\mathrm{Y} 1}+\mathrm{M}_{\mathrm{Z} 2}+\mathrm{M}_{\mathrm{Z3}}+\mathrm{M}_{\mathrm{Z4}_{4}}+\mathrm{M}_{\mathrm{Z5}}+\mathrm{M}_{\mathrm{Z6}}+\mathrm{M}_{\mathrm{Z} 7}+\mathrm{M}_{\mathrm{Z8}}+\mathrm{M}_{\mathrm{Z} 9}$

$\mathrm{XX}_{2 \mathrm{R}}=\mathrm{XX}_{2}-\mathrm{YY}_{2}-\left(\mathrm{m}_{3}+\mathrm{m}_{4}+\mathrm{m}_{8}+\mathrm{m}_{9}\right) \mathrm{d}_{3}{ }^{2}+\mathrm{XX}_{6}-\mathrm{YY}_{6}+\mathrm{XX}_{7}-\mathrm{YY}_{7}$ $\mathrm{XY}_{2 \mathrm{R}}=\mathrm{XY}_{2}+\mathrm{XY}_{6}+\mathrm{XY}_{7}$

$\mathrm{XZ}_{2 \mathrm{R}}=\mathrm{XZ}_{2}-\left(\mathrm{MZ}_{3}+\mathrm{MZ}_{4}+\mathrm{MZ}_{5}+\mathrm{MZ}_{6}+\mathrm{MZ}_{7}+\mathrm{MZ}_{8}+\mathrm{MZ}_{9}\right) \mathrm{d}_{3}+$

$\ldots \mathrm{XZ}_{6}+\mathrm{XZ}$

$\mathrm{YZ}_{2 \mathrm{R}}=\mathrm{YZ}_{2}+\mathrm{YZ}_{6}+\mathrm{YZ}_{7}$

$\mathrm{ZZ}_{2 \mathrm{R}}=\mathrm{ZZ}_{2}+\left(\mathrm{m}_{3}+\mathrm{m}_{4}+\mathrm{m}_{8}+\mathrm{m}_{9}\right) \mathrm{d}_{3}{ }^{2}+\mathrm{ZZ}_{6}+\mathrm{ZZ}_{7}+\mathrm{I}_{\mathrm{a} 2}$

$\mathrm{MX}_{2 \mathrm{R}}=\mathrm{MX}_{2}+\left(\mathrm{m}_{3}+\mathrm{m}_{4}+\mathrm{m}_{8}+\mathrm{m}_{9}\right) \mathrm{d}_{3}+\mathrm{MX}_{6}+\mathrm{MX}_{7}$

$f_{v 2 R}=f_{v 2}+f_{v 7}+f_{v 8}+f_{v 11}$

$\mathrm{f}_{\mathrm{c} 2 \mathrm{R}}=\mathrm{f}_{\mathrm{c} 2}+\mathrm{f}_{\mathrm{c} 7}+\mathrm{f}_{\mathrm{c} 8}+\mathrm{f}_{\mathrm{c} 11}$

$\mathrm{XX}_{3 \mathrm{R}}=\mathrm{XX}_{3}-\mathrm{YY}_{3}-\mathrm{d}_{4}{ }^{2} \mathrm{~m}_{4}+\mathrm{XX}_{5}-\mathrm{YY}_{5}-\mathrm{d}_{6}{ }^{2} \mathrm{~m}_{6}+\mathrm{XX}_{9}-\mathrm{YY}_{9}$

$\mathrm{XY}_{3 \mathrm{R}}=\mathrm{XY}_{3}+\mathrm{XY}_{5}+\mathrm{XY} \mathrm{Y}_{9}$

$\mathrm{XZ}_{3 \mathrm{R}}=\mathrm{XZ}_{3}-\mathrm{d}_{4} \mathrm{MZ}_{4}+\mathrm{XZ}_{5}-\mathrm{d}_{6} \mathrm{MZ}_{6}+\mathrm{XZ} \mathrm{Z}_{9}$

$\mathrm{YZ}_{3 \mathrm{R}}=\mathrm{YZ}_{3}+\mathrm{YZ}_{5}+\mathrm{YZ}_{9}$

$\mathrm{ZZ}_{3 \mathrm{R}}=\mathrm{ZZ}_{3}+\mathrm{m}_{4} \mathrm{~d}_{4}{ }^{2}+\mathrm{ZZ}_{5}+\mathrm{m}_{6} \mathrm{~d}_{6}{ }^{2}+\mathrm{ZZ}_{9}+\mathrm{I}_{\mathrm{a}}$

$M X_{3 \mathrm{R}}=\mathrm{MX}_{3}+\mathrm{m}_{4} \mathrm{~d}_{4}+\left(\mathrm{d}_{6} / \mathrm{d}_{3}\right) \mathrm{MX}_{6}+\mathrm{MX}_{9}$

$\mathrm{MY}_{3 \mathrm{R}}=\mathrm{MY}_{3}+\mathrm{MY}_{9}$

$\mathrm{f}_{\mathrm{v} 3 \mathrm{R}}=\mathrm{f}_{\mathrm{v} 3}+\mathrm{f}_{\mathrm{v} 6}+\mathrm{f}_{\mathrm{v} 10}$

$\mathrm{f}_{\mathrm{c} 3 \mathrm{R}}=\mathrm{f}_{\mathrm{c} 3}+\mathrm{f}_{\mathrm{c} 6}+\mathrm{f}_{\mathrm{c} 10}$.

$\mathrm{MX}_{5 \mathrm{R}}=\mathrm{MX}_{5}+\mathrm{m}_{6} \mathrm{~d}_{6}-\left(\mathrm{d}_{6} / \mathrm{d}_{3}\right) \mathrm{MX}_{6}$

$f_{v 5 R}=f_{v 5}+f_{v 4}+f_{v 9}+f_{v 12}$

$\mathrm{f}_{\mathrm{c} 5 \mathrm{R}}=\mathrm{f}_{\mathrm{c} 5}+\mathrm{f}_{\mathrm{c4}}+\mathrm{f}_{\mathrm{c} 9}+\mathrm{f}_{\mathrm{c} 12}$

$M Y_{8 R}=M Y_{8}-\left(d_{7} / d_{3}\right) M X_{7}$

The parameters having no effect on the dynamic model are: $\mathrm{XX}_{1}, \mathrm{XY}_{1}, \mathrm{XZ}_{1}, \mathrm{YY}_{1}, \mathrm{YZ}_{1}, \mathrm{MZ}_{1}, \mathrm{~m}_{1}, \mathrm{XY}_{4}, \mathrm{XZ}_{4}, \mathrm{YZ}_{4}, \mathrm{ZZ}_{4}$, $\mathrm{XY}_{8}, \mathrm{XZ}_{8}, \mathrm{YZ}_{8}, \mathrm{ZZ}_{8}, \mathrm{MX}_{4}$ and $\mathrm{MX}_{8}$.

\section{IDENTIFICATION METHOD AND EXPERIMENTAL RESULTS}

\section{A. Theory}

Generally, ordinary least-squares (LS) technique is used to estimate the minimum inertial parameters solving an overdetermined linear system obtained from a sampling of the dynamic model, along a given trajectory $(\mathbf{q}, \dot{\mathbf{q}}, \ddot{\mathbf{q}})$ [8]-[9]. $\mathbf{X}$ being the $b$ base parameters vector to be identified (same vector as $\chi$ ), $\mathbf{Y}$ the measurements vector (obtained by concatenation of the torques vector $\Gamma$ over the whole trajectory), $\mathbf{W}$ the observation matrix (obtained by concatenation of the linear regressor over the whole trajectory) and $\rho$ the vector of errors, the system is described as follows:

$$
\mathbf{Y}(\boldsymbol{\Gamma})=\mathbf{W}(\mathbf{q}, \dot{\mathbf{q}}, \ddot{\mathbf{q}}) \mathbf{X}+\mathbf{\rho}
$$


The L.S. solution $\hat{\mathbf{X}}$ minimizes the 2-norm of the vector of errors $\rho$. $\mathbf{W}$ is a $\mathbf{r} \times \mathbf{b}$ full rank and well conditioned matrix, obtained by tracking exciting trajectories and by considering the minimum inertial parameters, $r$ being the number of samplings along a trajectory. Hence, there is only one solution $\hat{\mathbf{X}}$ [9]. Standard deviations $\sigma_{\hat{\mathrm{X}}_{i}}$ are estimated using classical and simple results from statistics. The matrix $\mathbf{W}$ is supposed deterministic, and $\boldsymbol{\rho}$, a zero-mean additive independent noise, with a standard deviation such as:

$$
\mathbf{C}_{\boldsymbol{\rho}}=\mathrm{E}\left(\boldsymbol{\rho} \boldsymbol{\rho}^{\mathrm{T}}\right)=\sigma_{\boldsymbol{\rho}}^{2} \mathbf{I}_{\mathrm{r}}
$$

where $\mathrm{E}$ is the expectation operator and $\mathbf{I}_{\mathbf{r}}$, the $\mathbf{r} \times \mathbf{r}$ identity matrix. An unbiased estimation of $\sigma_{\rho}$ is:

$$
\sigma_{\rho}^{2}=\frac{\|\mathbf{Y}-\mathbf{W} \hat{\mathbf{X}}\|^{2}}{(\mathbf{r}-b)}
$$

The covariance matrix of the standard deviation is calculated as follows:

$$
\mathbf{C}_{\hat{\mathbf{X}} \mathbf{x}}=\sigma_{\mathbf{p}}^{2}\left(\mathbf{W}^{\mathbf{T}} \mathbf{W}\right)^{-1}
$$

$\sigma_{\hat{\mathrm{X}} \mathrm{i}}^{2}=\mathrm{C}_{\hat{\mathrm{X}} \hat{\mathrm{X}}_{\mathrm{ii}}}$ is the $\mathrm{i}^{\text {th }}$ diagonal coefficient of $\mathbf{C}_{\hat{\mathbf{X}} \hat{\mathbf{X}}}$. The relative standard deviation $\% \sigma_{\hat{X}_{\mathrm{r}}}$ is given by:

$$
\% \sigma_{\hat{\mathrm{X}}_{\mathrm{jr}}}=100 \frac{\sigma_{\hat{\mathrm{X}}_{\mathrm{j}}}}{\left|\mathrm{X}_{\mathrm{j}}\right|}
$$

However, in practice, $\mathbf{W}$ is not deterministic. This problem can be solved by filtering the measurement matrix $\mathbf{Y}$ and the columns of the observation matrix $\mathbf{W}$ as described in [9].

\section{B. Experimental results}

Exciting trajectories are designed by mixing triangular and sinus trajectories with various frequencies and amplitudes. Triangular positions give constant velocities and excite well gravity and friction parameters, while sinus positions give sinus accelerations and excite well inertia parameters.

The friction model is identified thanks to the method described in [19]. It consists in measuring the motorized joint torques at different constant velocities. Hence, we have used triangular trajectories with various amplitudes and frequencies. Experiences show that in our case, nonlinear effects are negligible. Therefore, a classical static model (viscous and Coulomb) is sufficient. In addition, it comes that the friction of passive joints proves to be negligible.

Appropriate data treatment was designed as in [9] and [20]. For each branch, $\mathbf{W}$ is a $(16000 \times 34)$ matrix and its conditioning number is close to 50 . The trajectories are thus enough exciting for identifying the base parameters of each branch [16]. The identified values of the upper branch are summed up in Table 1 while the identified values of the lower branch are summed up in Table 2. Parameters offset ${ }_{1}, \mathrm{MY}_{\mathrm{j}}$ (excepted $M Y_{1 R}$ ) $, f_{v 3 R}, f_{c 3 R}$, viscous damping and nondiagonal components of inertia tensor are missing because they are small compared to the others. We checked that when identified they have a large relative deviation, and that when removed from the identification model, the estimation of the other parameters is not perturbed. We checked also that inertia and gravity values are compatible with those obtained from $\mathrm{CAD}$.

Direct comparisons have been performed. These tests consist in comparing the measured and the estimated torques just after the identification procedure. An example for the arm of the lower branch is illustrated Fig. 5. We show that the estimated torque follows the measured torque closely.

Cross tests validations have been also performed. They consist in comparing the experimental data obtained along a trajectory not used during the identification procedure and data reconstructed from the identified parameters. Results obtained for the forearm of the upper branch (given in Fig. 6) show that the estimated torque follows the measured torque closely.

TABLE 1: IDENTIFIED VALUES FOR THE UPPER BRANCH

\begin{tabular}{cccc}
\hline \hline Parameters & $\begin{array}{c}\mathrm{CAD} \\
\text { Value }\end{array}$ & $\begin{array}{c}\text { Identified } \\
\text { Value }\end{array}$ & $\begin{array}{c}\text { Relative } \\
\text { deviation }\end{array}$ \\
\hline $\mathrm{ZZ}_{1 \mathrm{R}}(\mathrm{Kgm} 2)$ & 0.050 & 0.051 & $0.51 \%$ \\
$\mathrm{MX}_{1 \mathrm{R}}(\mathrm{Kgm})$ & 0.0 & 0.006 & $4.0 \%$ \\
$\mathrm{MY}_{1 \mathrm{R}}(\mathrm{Kgm})$ & 0.03 & 0.0300 & $1.0 \%$ \\
$\mathrm{f}_{\mathrm{C} 1}(\mathrm{Nm})$ & $0.12^{*}$ & 0.12 & $0.5 \%$ \\
$\mathrm{XX}_{2 \mathrm{R}}(\mathrm{Kgm} 2)$ & -0.023 & -0.023 & $1.1 \%$ \\
$\mathrm{ZZ}_{2 \mathrm{R}}(\mathrm{Kgm} 2)$ & 0.03 & 0.029 & $1.0 \%$ \\
$\mathrm{MX}_{2 \mathrm{R}}(\mathrm{Kgm})$ & -0.02 & -0.019 & $2.0 \%$ \\
$\mathrm{f}_{\mathrm{C} 2 \mathrm{R}}(\mathrm{Nm})$ & $0.11^{*}$ & 0.11 & $0.9 \%$ \\
offset $_{2}(\mathrm{Nm})$ & 0.03 & 0.0200 & $1.0 \%$ \\
$\mathrm{XX}_{3 \mathrm{R}}(\mathrm{Kgm} 2)$ & -0.012 & -0.011 & $1.1 \%$ \\
$\mathrm{ZZ}_{3 \mathrm{R}}(\mathrm{Kgm} 2)$ & 0.014 & 0.014 & $0.4 \%$ \\
$\mathrm{MX}_{3 \mathrm{R}}(\mathrm{Kgm})$ & 0.04 & 0.039 & $0.41 \%$ \\
$\mathrm{MX}_{5 \mathrm{R}}(\mathrm{Kgm})$ & 0.07 & 0.068 & $0.46 \%$ \\
$\mathrm{f}_{\mathrm{C} \mathrm{R}}(\mathrm{Nm})$ & $0.11^{*}$ & 0.11 & $0.5 \%$ \\
offset $_{5}(\mathrm{Nm})$ & 0.03 & 0.030 & $1.10 \%$ \\
\hline \hline
\end{tabular}

TABLE 2: IDENTIFIED VALUES FOR THE LOWER BRANCH

\begin{tabular}{cccc}
\hline \hline Parameters & $\begin{array}{c}\mathrm{CAD} \\
\text { Value }\end{array}$ & $\begin{array}{c}\text { Identified } \\
\text { Value }\end{array}$ & $\begin{array}{c}\text { Relative } \\
\text { deviation }\end{array}$ \\
\hline $\mathrm{ZZ}_{1 \mathrm{R}}(\mathrm{Kgm} 2)$ & 0.046 & 0.046 & $0.65 \%$ \\
$\mathrm{MX}_{1 \mathrm{R}}(\mathrm{Kgm})$ & 0.0 & -0.005 & $11.0 \%$ \\
$\mathrm{MY}_{1 \mathrm{R}}(\mathrm{Kgm})$ & -0.04 & -0.040 & $0.42 \%$ \\
$\mathrm{f}_{\mathrm{C} 1}(\mathrm{Nm})$ & $0.14^{*}$ & 0.13 & $0.30 \%$ \\
$\mathrm{XX}_{2 \mathrm{R}}(\mathrm{Kgm} 2)$ & -0.021 & -0.021 & $1.2 \%$ \\
$\mathrm{ZZ}_{2 \mathrm{R}}(\mathrm{Kgm} 2)$ & 0.028 & 0.027 & $0.47 \%$ \\
$\mathrm{MX}_{2 \mathrm{R}}(\mathrm{Kgm})$ & -0.025 & -0.023 & $0.95 \%$ \\
$\mathrm{f}_{\mathrm{C} \mathrm{R}}(\mathrm{Nm})$ & $0.11^{*}$ & 0.11 & $0.65 \%$ \\
offset $_{2}(\mathrm{Nm})$ & 0.03 & 0.020 & $3.0 \%$ \\
$\mathrm{XX}_{3 \mathrm{R}}(\mathrm{Kgm} 2)$ & -0.01 & -0.010 & $2.1 \%$ \\
$\mathrm{ZZ}_{3 \mathrm{R}}(\mathrm{Kgm} 2)$ & 0.012 & 0.012 & $0.46 \%$ \\
$\mathrm{MX}_{3 \mathrm{R}}(\mathrm{Kgm})$ & 0.035 & 0.034 & $1.0 \%$ \\
$\mathrm{MX}_{5 \mathrm{R}}(\mathrm{Kgm})$ & 0.07 & 0.067 & $0.5 \%$ \\
$\mathrm{f}_{\mathrm{C} 5 \mathrm{R}}(\mathrm{Nm})$ & $0.10^{*}$ & 0.11 & $0.5 \%$ \\
offset $_{5}(\mathrm{Nm})$ & 0.03 & 0.020 & $1.00 \%$ \\
\hline \hline
\end{tabular}


We note that the experimental results for the upper and lower branch are close to each other. The differences may be due to small differences between machined parts of the upper and lower branches (due to the symmetrical nature of the two branches, some results are of opposite sign). The symbol * means that these values have been identified through the method described in [19].

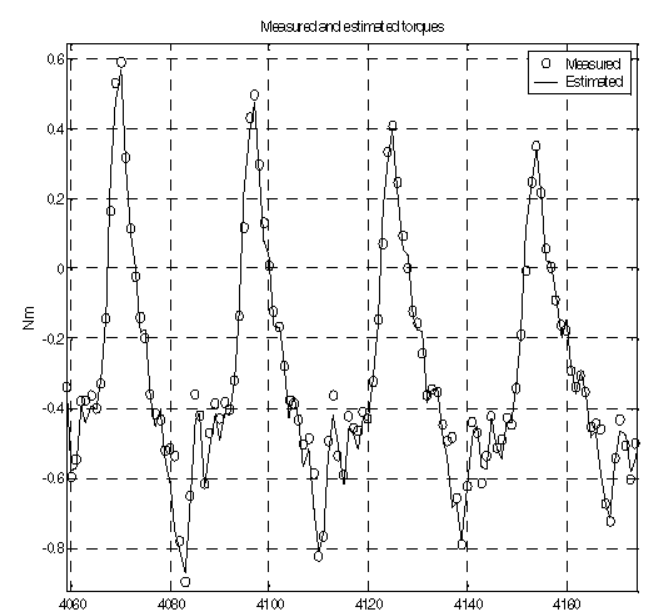

Fig. 5: Direct comparison validation, compares the measured and estimated torques applied to the arm of the lower branch

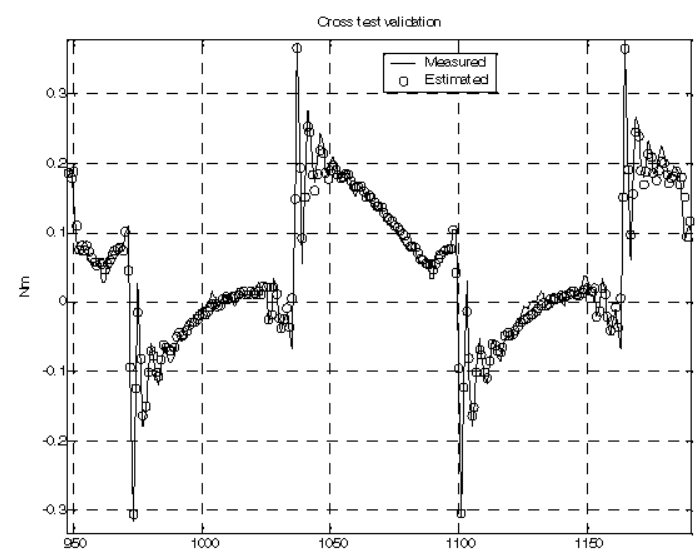

Fig. 6: Cross test validation, compares the measured and estimated torques applied to the forearm of the upper branch

\section{Characterization OF THE INTERFACE}

Knowing the values of the minimum inertial parameters, it is possible to calculate the apparent mass and operational friction felt by the operator. This characterizes the distortion introduced by the haptic interface. In the operational space, the model of each branch can be written as following:

$$
F_{o p}=M_{o p} \cdot \ddot{X}+B_{o p} \cdot \dot{X}+K_{o p} \cdot X+F_{c o p} \cdot \operatorname{sign}(\dot{X})+F_{d}
$$

Where $\mathbf{F}_{\mathrm{op}}$ is the force applied by the operator, $\mathbf{X}, \dot{\mathbf{X}}$ and $\ddot{\mathbf{X}}$ are respectively the position, velocity and acceleration vector in the operational space, $\mathbf{M}_{\mathbf{o p}}$ is the (3x3) apparent mass matrix

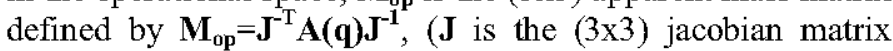
equals to $\mathbf{J}=\partial \mathrm{f}(\mathrm{q}) / \partial \mathrm{q}), \mathbf{B}_{\mathbf{o p}}$ is the apparent viscous friction matrix which equals to $\mathbf{B}_{\mathrm{op}}=\mathbf{J}^{-\mathrm{T}} \mathbf{F}_{\mathbf{V}} \mathbf{J}^{-1}, \mathbf{K}_{\mathrm{op}}$ is the operational stiffness matrix given by $\mathbf{K}_{\mathrm{op}}=\mathbf{J}^{-\mathrm{T}} \mathbf{K}_{\text {tot }} \mathrm{J}^{-\mathbf{1}}$ ( $\mathbf{K}_{\text {tot }}$ represents the global stiffness of the device, defined by $\left.\mathbf{K}_{\text {tot }} \Delta \mathbf{q}=\mathbf{J}^{\mathrm{T}} \mathbf{F}_{\mathrm{op}}-\boldsymbol{\Gamma}\right)$ and $\mathbf{F}_{\text {cop }}=\mathbf{J}^{-\mathrm{T}} \mathbf{F}_{\mathrm{c}}$ is the operational Coulomb friction matrix.

$$
\mathbf{F}_{\mathrm{d}}=\mathbf{J}^{-\mathrm{T}}(\mathbf{H}(\mathbf{q}, \dot{\mathbf{q}})-\mathbf{A}(\mathbf{q}) \dot{\mathbf{J}} \dot{\mathbf{q}})
$$

$\mathbf{F}_{\mathbf{d}}$ given by (19), is the torque neglected in the linear characterization of operational dynamics of the interface. The greater the velocity and angular range, the higher the disturbance will be.

The apparent mass, the operational stiffness and friction felt by the operator, can be calculated at all configurations in the workspace. In order to illustrate the interest of this approach the details about the apparent inertia are given.

Fig. 7 shows the maximum values of the diagonal components (called respectively Mxx, Myy and Mzz) obtained through SVD decomposition of the apparent mass matrix when $\mathrm{q}_{2}$ or $\mathrm{q}_{3}$ varies around a natural operator's position.
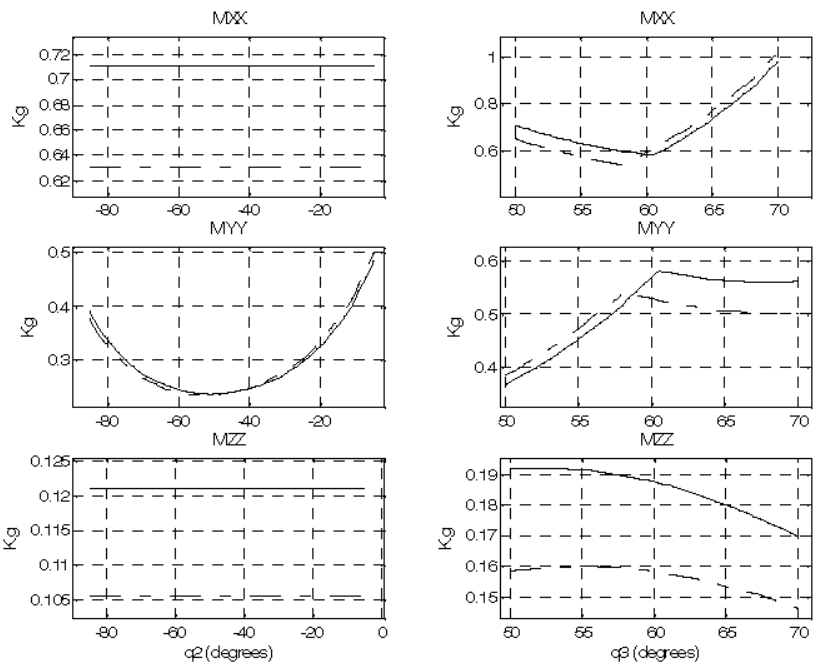

Fig. 7. Apparent mass around a natural position: upper branch (solid line) and lower branch (dashed line)

When $\mathrm{q}_{2}$ varies while $\mathrm{q}_{3}$ is fixed at a constant position, the maximum weight felt by the operator is close to $710 \mathrm{~g}$. This value is mainly due to the masses of the extremities of the links of the structure (see the regrouping formulas). Due to limited reduction ratios, the apparent mass resulting from the inertia of the rotors of the motors is limited, as well as the apparent mass of the counter-weights which are compensating the gravity effect. Although their masses are close to $1 \mathrm{Kg}$, their inertial effect is limited due to their proximity with the rotation axes. We observe that the performances are quite homogeneous. Hence, when moving only the arm of the medical interface, the operator is weakly disturbed by the variation of the apparent mass. 
When $q_{3}$ varies while $q_{2}$ is fixed at a constant position, the minimum weight felt by the operator is close to $600 \mathrm{~g}$. But, the performances are not homogeneous. Thus, when moving only the forearm of the medical interface, the operator is disturbed by the variation of the apparent mass. Indeed, this variation is close to $500 \mathrm{~g}$ and can reach $1 \mathrm{Kg}$. So, in order to compensate this undesirable effect, a control law is needed.

Once again, the performances of the upper branch are close to those of the lower branch.

Finally, thanks to the identification procedure described along this paper, we can model the branches of the medical interface exhibiting a complex architecture and evaluate their performances at each point of the workspace.

\section{CONCLUSION}

Experimental results given along this paper show that it is possible to apply a modeling and an identification method used for industrial robots for characterizing haptic devices. Indeed, associated with a proper parametric model, the identified values can be used to evaluate the distortion introduced by the device. It is thus possible to assess the qualities and drawbacks of the interface and to improve its design. It is also possible to compensate adverse effects by appropriate control laws.

One important aspect of the proposed methodology is that no specific assumption is made. Indeed, the parallelogram loops as all base parameters were taken into account in the modeling. Therefore, the protocol exhibited along this paper can be applied to any haptic device.

The identification protocol exposed along this paper is not limited to mechanical systems. For instance, it was successfully applied to a synchronous machine in [17] and it was compared with another identification method [18].

However, to apply correctly this identification method, position, current measurements and exciting trajectories are needed. In addition, the identification was made under the rigid modeling hypothesis which is valid in a frequency range [20].

Future works concern the use of this method to identify the 6 DOFs medical interface. In addition, the structural flexibility will be identified in order to determinate its influence in the haptic rendering. Several techniques of identification of localized flexibilities have been designed and tested in [20] and could be extended to multi degrees of freedom.

\section{REFERENCES}

[1] P.A. Millman, M. Stanley and JE. Colgate, "Design of a high performance haptic interface to virtual environments", IEEE Annual Virtual Reality Symposium, 1993, p. 216-222

[2] J. Colgate and G. Schenkel, "Passivity of a class of sampled data systems: application to haptic interfaces", American Control Conference, Baltimore 1994, p. 3236-3240

[3] N. Diolaitti, G. Niemayer, F. Barbagli and J. Kenneth Salisbury, "A criterion for the passivity of haptic devices", Proc. IEEE Int. Conf. on Robotics and Automation, 2005, p. 2463-2468

[4] M. Moreyra and B. Hannaford, "A practical measure of dynamic response of haptic devices", Proc. IEEE Int. Conf. on Robotics and Automation, Leuven, 1998, p.369-374

[5] A. Frisoli and M. Bergamasco, "Experimental identification and evaluation of performance of a 2 dof haptic display", Proc. IEEE Int. Conf. on Robotics and Automation, 2003, p. 3260-3265

[6] C.D. Lee, D.A. Lawrence and L.Y. Pao, "Dynamic modeling and parameter identification of a parallel haptic interface", Proc. $10^{\text {th }}$ Symp. Haptic Interfaces for Virtual Environments and Teleoperator Systems, IEEE Virtual Reality Conf., Orlando, 2002, p. 172-179

[7] A.M. Tahmasebi, B. Taati, F. Mobasser and K. Hashtrudi-Zaad, "Dynamic parameter identification and analysis of a PHANToM ${ }^{\mathrm{TM}}$ haptic device", Proc. IEEE Conf. on Control Applications, Toronto, August 2005, pp. 1251-1256

[8] M. Gautier, W. Khalil and P. P. Restrepo, "Identification of the dynamic parameters of a closed loop robot", Proc. IEEE on Int. Conf. on Robotics and Automation, Nagoya, may 1995 , p. $3045-3050$

[9] M. Gautier, "Dynamic identification of robots with power model", Proc. IEEE Int. Conf. on Robotics and Automation, Albuquerque, 1997, p. 1922-1927

[10] F. Khatounian et al., "Parameter identification of a single degree of freedom haptic interface", $14^{\text {th }}$ IFAC Symp. on System Identification, SYSID 2006, Newcastle, Australia, 2006, p. 249-254

[11] F. Bennis and W. Khalil, "Minimum inertial parameters of robots with parallelogram closed loop", IEEE Trans. On Systems, Man and Cybernetics, Vol. SMC 21, 1991, p., 318-326

[12] F. Gosselin, C. Bidard, J. Brisset, "Design of a high fidelity haptic device for telesurgery", IEEE Int. Conf. on Robotics and Automation, Barcelone 2005 , p. 206-211

[13] W. Khalil et J.F. Kleinfinger, "A new geometric notation for open and closed loop robots", In: IEEE Int. Conf. On Robotics and Automation, San Francisco USA, April 1986, pp. 1147-1180.

[14] M. Gautier and W. Khalil, "Direct calculation of minimum set of inertial parameters of serial robots", IEEE Transactions on Robotics and Automation, Vol. 6(3), June 1990.

[15] M. Gautier , "Numerical calculation of the base inertial parameters", Journal of Robotics Systems, Vol. 8, august 1991, p. 485-506

[16] M. Gautier and W. Khalil, "Exciting trajectories for the identification of base inertial parameters of robots", In: Proc. Of the $30^{\text {th }}$ Conf. on Decision and Control, Brigthon, England, December 1991, pp. 494-499.

[17] F. Khatounian, S. Moreau, E. Monmasson, A. Janot and F. Louveau, "Simultaneous Identification of the Inertial Rotor Position and Electrical Parameters of a PMSM for a Haptic Interface", In: $12^{\text {th }}$ EPE-PEMC Conference, Portoroz, Slovenia, August September 2006, CD-ROM, ISBN 1-4244-0121-6.

[18] F. Khatounian, S. Moreau, E. Monmasson, A. Janot and F. Louveau, "Parameters Estimation of the Actuator Used in Haptic Interfaces: Comparison of two Identification Methods", In: ISIE 2006, Montreal, Canada, August September 2006

[19] R. Specht, and R. Isermann, "On-line identification of inertia, friction and gravitational forces applied to an industrial robot", Proc. IFAC Symp. on Robot Control, SYROCO'88, 1988, p. 88.1-88.6

[20] M.T. Pham, M. Gautier and P. Poignet, "Identification of joint stiffness with band pass filtering", Proc. IEEE on Int. Conf. on Robotics and Automation, Seoul, may 2001, p. 2867-2872 